\title{
LOCAL ANAESTHETIC SYSTEMIC TOXICITY: CURRENT CONCEPTS AND MANAGEMENT
}

Lakshmi Mahajan¹, Ruchi Gupta², Anita Kumari³ ${ }^{3}$, Chiteshwar Walia ${ }^{4}$, Jagdeep Sharma5, Amrinder Singh 6

\section{HOW TO CITE THIS ARTICLE:}

Lakshmi Mahajan, Ruchi Gupta, Anita Kumari, Chiteshwar Walia, Jagdeep Sharma, Amrinder Singh. "Local Anesthetic Systemic Toxicity: Current Concepts and Management". Journal of Evolution of Medical and Dental Sciences 2014; Vol. 3, Issue 11, March 17; Page: 2840-2850, DOI: 10.14260/jemds/2014/2215

ABSTRACT: Local anesthetics are one of the most commonly used drugs in the field of medicine. Local anesthetics are widely used to induce anesthesia and analgesia for surgical procedures and pain management. Local an aesthetic systemic toxicity (LAST) is a rare but potentially fatal complication of regional anesthesia and has been recognized and reported since the late1800s. This narrative review summarizes the pharmacology of local anesthetics, clinical manifestations of systemic toxicity associated with these agents, necessary preventive measures and recent treatment strategies.

KEYWORDS: Local anesthesia; Toxicity; Lipid emulsion; Prevention; Treatment.

INTRODUCTION: Local anesthesia as an alternative to general anesthesia has proved beneficial for both patients and doctors. LA drugs are generally safe when used in normal doses but unintentional over dosing results in high plasma concentration of drug which may lead to spectrum of toxicity ranging from localized reactions such as edema and dermatitis to neurological and cardiac complications with potential adverse effects. Unexpected local anesthetic toxicity can also occur where the pharmacokinetics of the drug is altered by co-morbid states such as cardiac, renal or hepatic failure. Vigilance during the performance of regional anesthesia and immediate intervention at the earliest sign of toxicity improves the chances of successful treatment.

Historical perspectives of local anesthetics: Cocaine was isolated from the cocoa leaf by the German chemist, Albert Niemann in 1860 and in 1884; it was used clinically for the first time by the Viennese ophthalmologist, Carl Koller, when he performed the first surgical procedure using local anesthesia on a patient with glaucoma. Portentously, however, 200 cases of systemic toxicity and 13 deaths were assigned to the drug during the period from 1884 to $1891^{1}$. In 1904, another German chemist, Alfred Einhorn, synthesized the compound, novocaine, later known as procaine in the United States during World War 1. In 1943, the first amino-amide local anesthetic lidocaine was isolated. In1957, bupivacaine was synthesized by Bo afEkenstam and introduced into clinical practice ten years later. In 1979, George Albright highlighted five anecdotal reports of cardiac arrest following regional anesthesia with bupivacaine. These cases of almost simultaneous convulsions and cardiac arrest required prolonged and largely unsuccessful resuscitation following a presumed intravascular injection, illustrating the narrow margin that exists for bupivacaine-induced cerebral and cardiac toxicity. In October 1983, in an address to the United States Food and Drug Administration's Anesthetic and Life Support Advisory Committee, Albright presented a series of 49 reports of cardiac arrest or ventricular tachycardia requiring cardio version that occurred over the previous ten years. Most of these cases involved obstetric epidural anesthesia using $0.75 \%$ bupivacaine. 
In 1920s American Medical Association (AMA) established the Committee for the Study of Toxic Effects of Local Anesthetics ${ }^{2}$. Records from the American Society of Anesthesiologists Closed Claims Database show that between 1980 and 2000; LAST was associated with one-third of the claims of death and brain damage after regional anesthesia. The estimate of clinically important local anesthetic toxicity is from 7.5 to 20 occurrences per 10, 000peripheral nerve blocks and approximately 4 occurrences per 10, 000 epidurals 3 .

The Association of Anesthetists of Great Britain and Ireland (AAGBI) in 2007 published the first set of standardized guidelines for severe LA toxicity 4 . In 2008, the American Society of Anesthesiologists Committee on Critical Care Medicine ${ }^{5}$, and Resuscitation Council of the United Kingdom ${ }^{6}$ also published protocols for the treatment of LAST. The American Society of Regional Anesthesia and Pain Medicine published practice advisory on LAST ${ }^{7}$. The guidelines emphasize on early cardiopulmonary resuscitation and the use of intravenous lipid emulsion in local anesthetic systemic toxicity. Moore and Bridenbaugh ${ }^{8}$ highlighted the importance of airway management and prevention of hypoxia and acidosis in treatment of LA systemic toxicity.

\begin{tabular}{|l|c|c|c|c|c|c|c|c|}
\hline $\begin{array}{c}\text { Local } \\
\text { Anesthetic }\end{array}$ & $\begin{array}{c}\text { Type of } \\
\text { Structure }\end{array}$ & $\begin{array}{c}\text { Half Life } \\
\text { (hours) }\end{array}$ & $\begin{array}{c}\text { Onset } \\
\text { Time }\end{array}$ & $\begin{array}{c}\text { Protein } \\
\text { Binding } \\
(\%)\end{array}$ & $\begin{array}{c}\text { Max. Dose } \\
(\mathrm{mg} / \mathrm{kg})\end{array}$ & $\begin{array}{c}\text { Duration } \\
\text { Of } \\
\text { Action }\end{array}$ & $\begin{array}{c}\text { pKa } \\
(25)\end{array}$ & $\begin{array}{c}\text { Max. Dose } \\
\text { (mg/kg)with } \\
\text { epinephrine }\end{array}$ \\
\hline Bupivacaine & Amide & 2.7 & Medium & $90-97$ & $1-2.5$ & Long & 8.1 & 2 \\
\hline L-bupivacaine & Amide & 1.3 & Medium & $>97$ & $2-2.5$ & Long & 8.1 & 2 \\
\hline Ropivacaine & Amide & 1.8 & Medium & 94 & $2.5-3$ & Long & 8.0 & 3 \\
\hline Prilocaine & Amide & 1.5 & Short & 55 & $5-7$ & Medium & 8.9 & \\
\hline Lignocaine & Amide & 1.6 & Short & $60-75$ & $4-5$ & Medium & 7.9 & 7 \\
\hline Cocaine & Ester & N/A & Long & N/A & $1.5-3$ & Long & N/A & 3 \\
\hline
\end{tabular}

Pharmacological properties of individual local anesthetics

*Dosing depends upon the clinical situation; higher doses may be allowed with the coadministration of epinephrine. N/A denotes not applicable.

\section{Determinants of systemic toxicity:}

I) Pharmacokinetic factors: The incidence and intensity of systemic drug toxicity generally depends on concentration of the drug in the free form. Tissue vascularity is another important consideration. The uptake of local anesthetic from greatest to least is as follows: blood/trachea > intercostal > caudal/paracervical $>$ epidural > perivascular brachial plexus $>$ sciatic $>$ subcutaneous. It is important to consider both "safe maximal" local anesthetic dose, vascularity of the tissue and site of administration. Amide-linked LAs are eliminated mainly through hepatic metabolism and ester linked LAs are degraded by plasma esterases. In patient having markedly impaired hepatic function, levels of the amide agents remain high. Anesthetic activity of LA also depends on dissociation constant (pKa), $\mathrm{pH}$, lipid solubility, vascularity at injection site, and protein binding.

Patient specific conditions can influence the systemic uptake and toxicity of even appropriately administered LAs. Conditions that affect the binding of amide linked LAs to albumin 
and $\alpha 1$ acid glycoprotein also affects the free concentration of drug. Pregnant women have a high cardiac output which accelerates the vascular absorption of drugs from tissues ${ }^{9}$. Also the gravid uterus causes epidural venous distension, decreasing LA required to achieve a given level of neural blockade ${ }^{10}$.Pregnancy also diminishes the protein binding of bupivacaine, so sensitivity for cardiac toxicity increases ${ }^{11,12}$.Gestation is also thought to aggravate myocardial and neuronal toxicity to some LAs, possibly because of effect of progesterone ${ }^{13,14}$.

In renal failure, cardiac output rises to compensate for anemia which increases the systemic uptake of LA from tissues, hence shortening the duration of local and regional anaesthesia9. Renal failure also reduces the excretion and metabolism of LAs. Other factors like heart failure, $\beta$ adrenergic-blocking drugs and ageing retard the clearance of LA by reducing cardiac output and hepatic perfusion ${ }^{15}$.

II) Pharmacodynamic factors: Stereoisomerism contributes to different pharmacological activity of local anesthetics and is an important factor to decide the relative potency. Local anesthetics have three basic components to their chemical structure: a lipophilic (aromatic) end, a hydrophilic (amine) end and a link between the two ends. High molecular weight LAs are more lipid soluble. They readily cross cell membranes and has increased affinity for binding ion channels which increases the potency for LAST ${ }^{16}$. Bupivacaine molecule has an asymmetric (chiral) carbon so there are two stereoisomers of this anesthetic; with the (S-) enantiomer (levobupivacaine) generally considered to bear a lesser propensity to induce severe systemic toxicity than the $(\mathrm{R}+)$ enantiomer or the standard racemic mixture. Ropivacaine, a derivative of bupivacaine, is also commercially produced in the form of its $(\mathrm{S}-)$ enantiomer. In studies on isolated mammalian hearts, $(\mathrm{R}+)$ bupivacaine was found to be more arrhythmogenic than levobupivacaine ${ }^{17-19}$.

Central Nervous System Toxicity by Las: The central nervous system is more sensitive to LA toxicity than the cardiovascular system ${ }^{20}$. Therefore CNS manifestations tend to occur earlier. Toxic response of the central nervous system to local anesthetic effect is a complex interplay between excitatory and inhibitory pathways ${ }^{21}$.CNS toxicity is biphasic because LAs first block sodium channels present in the inhibitory neurons which allows the excitatory neurons to act unopposed and creating an excitatory state. Consequently, both inhibitory and excitatory pathways get blocked which results in total CNS inhibition ${ }^{16}$.

Cardiac toxicity of local anesthetics: Cardiovascular toxicity produces changes in cardiac conduction, impairment of contractility and myocardial metabolic changes. Cardiotoxic effects of LA can be compared using the CC/CNS ratio (ratio of the dosage required for cardiovascular collapse and dosage that will produce convulsion). Lower is the ratio, the more cardiotoxic is the drug. Ratio of bupivacaine is 2.0, ropivacaine is 2.2, and lignocaine is 7.1. Bupivacaine acts by blocking SA node resulting in prolong PR interval, induces ventricular arrhythmias including fibrillation and re-entrant type of arrhythmias. The ascending order of cardiotoxicity is lignocaine, ropivacaine, levobupivacaine, bupivacaine22, 23. Classically CNS toxiciy precedes CVS toxicity. Agents with high potency, such as bupivacaine, etidocaine, and tetracaine are more cardiotoxic than less potent agents such as lidocaine, mepivacaine or prilocaine ${ }^{21}$. Cardiotoxicity, though infrequent; is more serious and 
difficult to treat. CVS toxicity like CNS toxicity is also biphasic with early excitation and then depression 24,25 .

The mechanism of cardiovascular toxicity is based on direct and indirect actions of LA on the myocardium and on vascular smooth muscle, but is not fully elucidated 26,27 . The cardiovascular toxicity is the effect of the blockade of sodium, potassium and calcium channels. The direct action on myocardium includes negative inotropic effect and conduction delay while the indirect action includes effect on the cardiac center in the middle brain ${ }^{28}$.

Calcium ion channel blockade is considered to be one of the main mechanisms of LA induced cardiac depression. This results in displacement of calcium from cardiac muscles causing decrease in myocardial contractility. The blockade of sodium ion channel reduces action potential duration and effective refractory period. Inhibition of cyclic adenosine monophosphate (cAMP) disrupts cell homeostasis. LA also causes conduction blockade which results in prolongation of conduction time, increases PR interval and QRS complex duration. Peripheral vasodilatation further worsens the hypotension.

\begin{tabular}{|l|l|}
\hline Central Nervous System & Cardiovascular System \\
\hline Feelings Of light-headedness & Shortness of breath \\
\hline Perioral tingling & Hypertension \\
\hline Tinnitus & Tachycardia \\
\hline Restlessness & Palpitation \\
\hline Disorientation & Chest pain \\
\hline Drowsiness & Severe Hypotension \\
\hline Abnormal taste & Syncope \\
\hline Convulsion & Sinus bradycardia \\
\hline Apnea & Arrhythmia \\
\hline Unconsciousness & Dysrhythmia \\
\hline Respiratory depression & Cardiac arrest \\
\cline { 1 - 1 } Respiratory arrest & \multicolumn{2}{|c|}{ Sign and Symptoms of LAST } \\
&
\end{tabular}

Diagnosis and differential diagnosis: The diagnosis of LA systemic toxicity is more of clinical assessment. However, there are many other complications which have similar clinical features as of LAST. The differential diagnosis of local anesthetics toxic reactions are as follows: ${ }^{29}$.

\begin{tabular}{|l|l|}
\hline \multicolumn{1}{|c|}{ Etiology } & \multicolumn{1}{c|}{ Clinical features } \\
\hline Anaphylaxis & $\begin{array}{l}\text { Itching, flushing, hives, edema, hypotension, } \\
\text { bronchospasm, anxiety, difficulty breathing }\end{array}$ \\
\hline Reaction to vasoconstrictors & $\begin{array}{l}\text { Headache, fear, apprehension, palpitations, } \\
\text { increased heart rate, elevated blood pressure }\end{array}$ \\
\hline Vasovagal reaction & $\begin{array}{l}\text { Light-headedness, bradycardia, hypotension, } \\
\text { sweating, pallor, syncope, nervousness }\end{array}$ \\
\hline
\end{tabular}


Local anesthetic toxicity

- Intravascular injection

- Relative overdose
Tinnitus, confusion, immediate convulsions cardiac arrhythmias Motor twitching, irritability, seizures, coma, cardiovascular collapse

\section{Recommendations for Diagnosing LAST ${ }^{30}$}

1. Classic descriptions of LAST depict a progression of subjective symptoms of CNS excitement (agitation, auditory changes, metallic taste, abrupt onset of psychiatric symptoms) followed by seizures or CNS depression (drowsiness, coma, or respiratory arrest). Near the end of this continuum, initial signs of cardiac toxicity (hypertension, tachycardia, or ventricular arrhythmias) are supplanted by cardiac depression (bradycardia, conduction block, systole, decreased contractility). However, there is substantial variation in this classic description, including the following:

- Simultaneous presentation of CNS and cardiac toxicity

- Cardiac toxicity without prodromal signs and symptoms of CNS toxicity

Thus, the practitioner must be vigilant for atypical or unexpected presentation of LAST. (I, B)

2. The timing of LAST presentation is variable. Immediate $(60 \mathrm{secs})$ suggests intravascular injection of LA with direct access to the brain, while presentation that is delayed 1-5 mins suggests intermittent or partial intravascular injection, delayed circulation time, or delayed tissue absorption. Because LAST can present 15 mins after injection, patients who receive potentially toxic doses of LA should be closely monitored for at least 30 mins after injection. (I, B)

3. Case reports associate LAST with underlying cardiac, neurologic, pulmonary, renal, hepatic, or metabolic disease. Heightened vigilance is warranted in these patients, particularly if they are at the extremes of age. (IIa, B)

4. The overall variability of LAST signs and symptoms, timing of onset and association with various disease states suggests that practitioners should maintain a low threshold for considering the diagnosis of LAST in patients with atypical or unexpected presentation of CNS or cardiac signs and symptoms after receiving more than a minimal dose of LA. (IIa, B)

The class of recommendation and level of evidence for each intervention are given in parenthesis.

The primary role of anesthesiologist is to avoid toxicity and secondly to treat it if it occurs. Immediate intervention at the earliest sign of LAST is of paramount importance and improves the chances of successful treatment. In patient with suspected LA toxicity, initial step is ensuring adequate ventilation and oxygenation, second step includes management of seizures, maintaining adequate coronary perfusion, treatment of dysrhythmias and hypotension.

\section{Recommendations for Preventing LAST 30}

1. There is no single measure that can prevent LAST in clinical practice. 
2. Use the lowest effective dose of local anesthetic (dose=product of volume and concentration) (I; C).

3. Use incremental injection of local anesthetics-administer 3-mL to 5-mL aliquots, pausing 1530secs between each injection. When using a fixed needle approach, eg, landmark, paresthesia-seeking, or electrical stimulation, time between injections should encompass circulation time (approximately 30-45 s); however, this ideal may be balanced against the risk of needle movement between injections. Circulation time may be increased with lowerextremity blocks. The use of larger dosing increments would dictate the need for longer intervals to reduce the cumulative dose from stacked injections before an event of LAST. Incremental injection may be less important with ultrasound guidance, given that frequent needle movement is often used with the technique (I; C).

4. Aspirate the needle or catheter before each injection, recognizing that there is approximately $2 \%$ false-negative rate for this diagnostic intervention $(\mathrm{I} ; \mathrm{C})$

5. When injecting potentially toxic doses of local anesthetic, use of an intravascular marker is recommended. Although epinephrine is an imperfect marker and its use is open to physician judgment, its benefits likely outweigh its risks in the majority of patients (IIa;B):

- Intravascular injection of epinephrine $10-15 \mathrm{mg} / \mathrm{mL}$ in adults produces $>10$-beat $\mathrm{HR}$ increase or a $>15-\mathrm{mm} \mathrm{Hg}$ SBP increase in the absence of b-blockade, active labor, advanced age, or general/neuraxial anaesthesia.

- Intravascular injection of epinephrine $0.5 \mu \mathrm{g} / \mathrm{kg}$ in children produces a $>15-\mathrm{mmHg}$ increase in SBP

- Subtoxic doses of LAs can produce subjective symptoms of mild systemic toxicity (auditory changes, excitation, metallic taste, etc.) in unpremedicated patients.

- Fentanyl $100 \mu \mathrm{g}$ produces sedation if injected intravasculary in labouring patients.

6. Ultrasound guidance may reduce the frequency of intravascular injection, but actual reduction of LAST remains unproven in humans. Individual reports describe LAST despite the use of ultrasound-guided regional anaesthesia. The overall effectiveness of ultrasound guidance in reducing the frequency of LAST remains to be determined (IIa; C).

The class of recommendations and level of evidence for each intervention are given in parenthesis

\section{Recommendations for Treatment of LAST30}

1. If signs and symptoms of LAST occur, prompt and effective airway management is crucial to preventing hypoxia and acidosis, which are known to potentiate LAST (I; B).

2. If seizures occur, they should be rapidly halted with benzodiazepines. If Benzodiazepines are not readily available, small doses of propofol or thiopental are acceptable. Future data may support the early use of lipid emulsion for treating seizures (I;B)

3. Although propofol can stop seizures, large doses further depress cardiac function; propofol should be avoided when there are signs of CV compromise (III; B). If seizures persist despite benzodiazepines, small doses of succinylcholine or similar neuromuscular blocker should be considered to minimize acidosis and hypoxemia.(I;C) 
4. If cardiac arrest occurs, we recommend standard advanced cardiac life support with the following modifications:

- If epinephrine is used, small initial doses (10-100 mg boluses in the adult) are preferred (IIa;C)

- Vasopressin is not recommended (III;B)

- Avoid calcium channel blockers and b-adrenergic receptor blockers (III;C)

- If ventricular arrhythmias develop, amiodarone is preferred (IIa;B); treatment with local anesthetics (lidocaine or procainamide) is not recommended (III;C)

5. Lipid emulsion therapy (IIa;B)

- Consider administering at the first signs of LAST, after airway management

- Dosing:

○ $\quad 1.5 \mathrm{~mL} / \mathrm{kg} 20 \%$ lipid emulsion bolus

$\circ 0.25 \mathrm{~mL} / \mathrm{kg} / \mathrm{min}$ of infusion continued for at least $10 \mathrm{~min}$ after circulatory stability is attained.

- If circulatory stability is not attained, consider another bolus and increasing infusion to $0.5 \mathrm{~mL} / \mathrm{kg} / \mathrm{min}$

○ Approximately $10 \mathrm{~mL} / \mathrm{kg}$ lipid emulsion for $30 \mathrm{~min}$ is recommended as the upper limit for initial dosing

6. Propofol is not a substitute for lipid emulsion (III;C)

7. Failure to respond to lipid emulsion and vasopressor therapy should prompt institution of CPB (IIa; B). Because there can be considerable lag in beginning CPB, it is reasonable to notify the closest facility capable of providing it when CV compromise is first identified during an episode of LAST.

The class of recommendations and level of evidence for each intervention are given in parenthesis.

Lipid emulsion therapy in management of cardiovascular toxicity: Discovery of lipid emulsion as therapeutic agent has shown promising results in the resuscitation of patients suffering from LA induced cardiovascular collapse. In 1998 Weinberg ${ }^{31}$ first reported that use of lipid emulsion infusion during resuscitation, increased the median lethal dose of bupivacaine in rats by50\%and increased the resistance of rats to bupivacaine induced asystole ${ }^{32}$. In 2006 Rosenblatt $^{33}$ and Litzet al ${ }^{34}$ reported successful clinical use of lipid emulsion to reverse local anesthetic induced cardiac arrest. Henceforth, frequent successful reports have provided support for this form of management for LAST caused by bupivacaine, levobupivacaine, and ropivacaine ${ }^{34-36}$. Early infusion of lipid might avoid progression of toxicity to cardiac arrest.

The exact mechanism of action of lipid emulsion therapy is not known. The efficacy of lipid in combating bupivacaine induced cardiac toxicity is thought in its ability to accelerate the washout of the LA from the myocardium. It may serve as a "circulating lipid sink", providing a large lipid phase in the plasma, so will draw lipophilic drugs out of hydrophilic plasma and making them unavailable to tissues $^{33}$. Other mechanism is that, the high lipid concentration forces lipid influx into cardiac myocyte with lipid overwhelming the LA blockade of the L-CAT enzyme and counter the impaired 
free fatty acid delivery caused by local anesthetics in the mitochondria, and enable energy production, which makes myocardium more susceptible to resuscitation ${ }^{37,38}$.

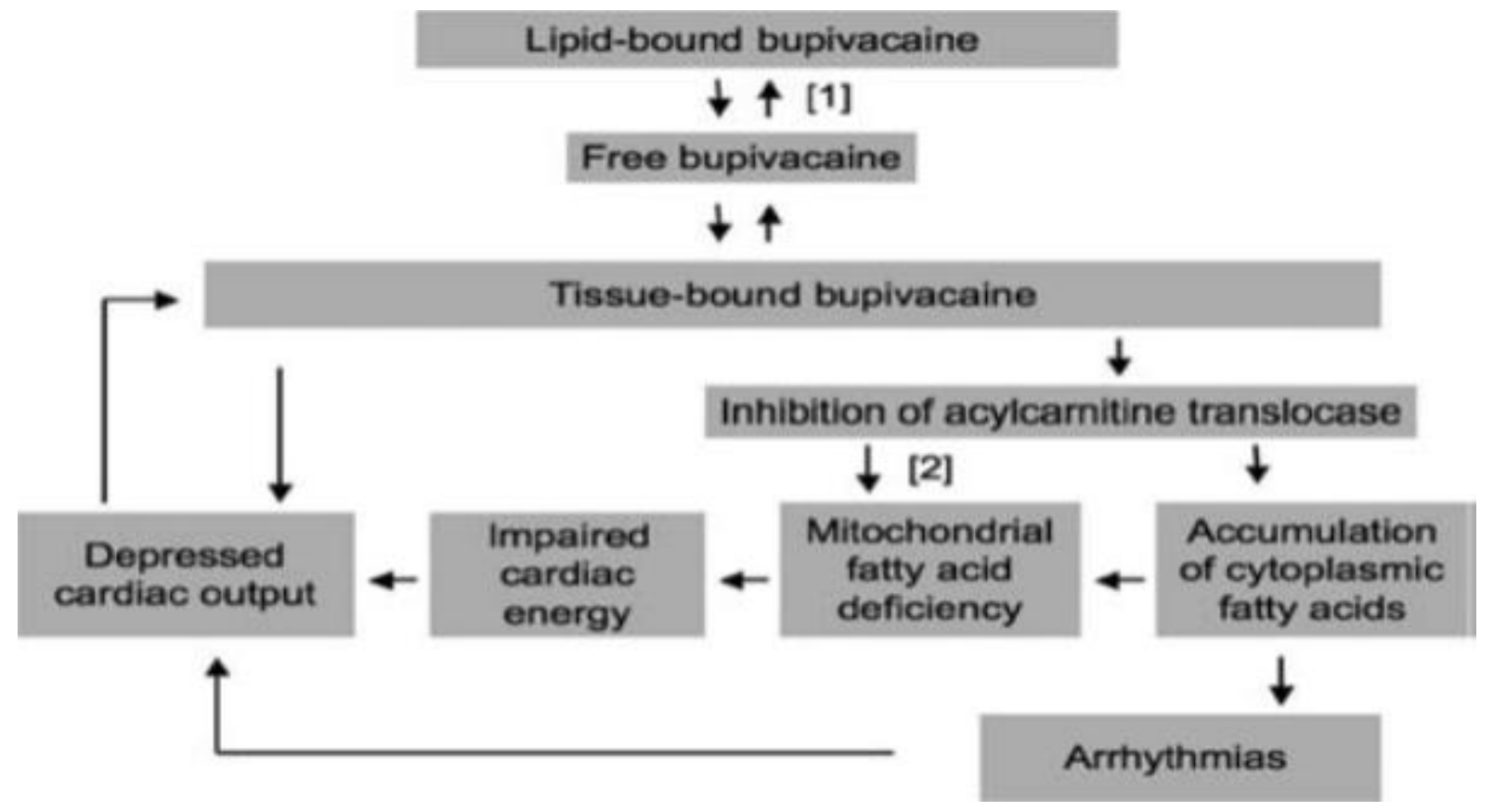

Sites of maintenance and potentiation of bupivacaine cardiotoxicity: Lipid intervention might exert a positive effect secondary to 2 postulated mechanisms: [1] lipid sink, with bupivacaine partitioned into lipid, reducing the effective unbound fraction available for binding to cardiac tissue; [2] Lipid-providing substrate, which may overcome the loss of cardiac energy because of the inhibition of acylcarnitine translocase by bupivacaine.

The commonly used lipid emulsion preparation is Intralipid 20\%. Propofol is not a suitable substitute for Intra lipid. According to studies, dose above $8 \mathrm{mg} / \mathrm{kg}$ is of no benefit. In the absence of further lipid emulsion, amiodarone and inotropic support were used to treat cardiotoxicity. Along with this regimen cardiopulmonary resuscitation should be continued. Lipid therapy complication may cause allergic reactions, liver function impairment, pancreatitis, hypercoagulability state and fluid overload. The extra caution is required to be taken in patients with severe hepatic disease, anemia, pulmonary disease and coagulopathy.

There is limited evidence available regarding use of lipid emulsion in children. There is 1 published report regarding successful lipid resuscitation of a 13-year-old girl with ECG changes after a brachial plexus block. Lipid emulsion has been successful in a neonate ${ }^{39}$ with severe cardiac compromise after caudal analgesia with bupivacaine. However, constituting safe dosing lipid therapy regimen is very important in neonates and children because complications from lipid overload have been reported in neonates receiving intravenous nutritional support ${ }^{40}$.

CONCLUSION: The safe and effective use of local anesthetics depends primarily on good clinical skills, proper dosage, correct technique, adequate precautions and readiness for emergencies. Numerous guidelines and protocols for the management of local anesthetic system ictoxicity have been published in recent years. All clinicians should be familiar, prior to use of local anesthetics, with 
these protocols and suitable quantities of lipid emulsion must be available in all areas where regional anesthesia is practiced. There is need for more experimental and clinical data to refine the therapeutic regimens of lipid therapy in the treatment of LAST to ensure the best outcome for the patient.

\section{REFERENCES:}

1. Ruetsch YA, Boni T, Borgeat A. From cocaine to ropivacaine: The history of local anesthetic drugs. Current topics in medicinal chemistry. 2001 Aug; 1(3):175-82.

2. Ireland P E, Ferguson J K, Stark E J. The clinical and experimental comparison of cocaine and pontocaine as topical anesthetics in otolaryngological practice. Laryngoscope 1951; 61:767-77

3. Mulroy MF. Systemic toxicity and cardiotoxicity from local anesthetics: incidence and preventive measures. Reg Anesth Pain Med 2002; 27:556-61.

4. Guidelines for the management of severe local anesthetic toxicity. The Association of Anesthetists of Great Britain \& Ireland; 2007.

5. Gabrielli A, O'Connor MF, Maccioli GA. Anaesthesia Advanced Circulatory Life Support. The American Society of Critical Care Anesthesiologists \& the American Society of Anesthesiologists, Committee on Critical care Medicine. Monograph as of February 2008.

6. Resuscitation Council (UK). Cardiac arrest or cardiovascular collapse caused by local anesthetic. 2008 Available at http://www.resus.org.uk/pages/caLocalA.htm

7. Neal J M, Bernards C M, Butterworth J F 4th. ASRA practice advisory on local anesthetic systemic toxicity. Regional Anesthesia \& Pain Medicine. 2010 March- April; 35(2):152-61

8. Moore Dc, Bridenbaugh LD. Oxygen: the antidote for systemic toxic reactions from local anesthetic drugs. JAMA. 1960 Oct; 174(1):842-7.

9. Pere P, Salonen M, Jokinen M, et al. Pharmacokinetics of ropivacaine in uremic and nonuremic patients after axillary brachial plexus block. Anesth Analg. 2003 Feb; 96(2):563-9.

10. Pihlajamaki K, Kanto J, Lindberg R, et al. Extradural administration of bupivacaine: Pharmacokinetics and metabolism in pregnant and non-pregnant women. Br J Anaesth. 1990 May; 64(5):556-62.

11. Denson D, Coyle D, Thompson G, Myers J. Alpha 1-acid glycoprotein and albumin in human serum bupivacaine binding. Clin Pharmacol Ther. 1984 May; 35(5):409-15.

12. Santos AC, Pedersen H, Harmon TW, et al. Does pregnancy alter the systemic toxicity of local anesthetics? Anesthesiology. 1989 Jun; 70(6):991-5.

13. Butterworth JF IV, Walker FO, Lysak SZ. Pregnancy increases median nerve susceptibility to lidocaine. Anesthesiology. 1990 Jun; 72(6):962-5.

14. Moller RA, Covino BG. Effect of progesterone on the cardiac electrophysiologic alterations produced by ropivacaine and bupivacaine. Anesthesiology. 1992 Oct; 77(4):735-41.

15. Rosenberg PH, Veering BT, Urmey WF: Maximum recommended doses of local anesthetics: A multifactorial concept. Reg Anesth Pain Med. 2004 Nov-Dec; 29(6):564-75.

16. S. Englesson. The influence of acid-base changes on central nervous systemic toxicity of local anesthetic agents. I. An experimental study in cats II. Acta Anaesthesiol Scand. 1974 June; 18(2):79-87. 
17. Zapata-Sudo G, Trachez MM, Sudo RG, Nelson TE. Is comparative cardiotoxicity of S (-) and R (+) bupivacaine related to enantiomer-selective inhibition of L-type Ca2+ channels? Anesth Analg. 2001 Feb; 92(2):496-501.

18. Graf BM, Martin E, Bosnjak ZJ, Stowe DF. Stereospecific effect of bupivacaine isomers on atrioventricular conduction in the isolated perfused guinea pig heart. Anesthesiology. $1997 \mathrm{Feb}$; 86(2):410-9.

19. Mazoit JX, Boico O, Samii K. Myocardial uptake of bupivacaine: II. Pharmacokinetics and pharmacodynamics of bupivacaine enantiomers in the isolated perfused rabbit heart. Anesth Analg. 1993 Sep; 77(3):477-82.

20. Covino BG. Toxicity of local anesthetics. Acta Anesthesiol Belg. 1998; 39(3); 152-62.

21. Derek Dillane D, Finucane B T. Local anesthetic systemic toxicity. J Can Anesth. 2010 Feb; 57(4); 368-80.

22. Casati A, Putzu M. Bupivacaine, levobupivacaine and ropivacaine: are they clinically different? Best Pract Res Clin Anesthesiology. 2005 Jun; 19(2):247-68.

23. Zink W, Graf BM. The toxicology of local anesthetics: the place of ropivacaine and levobupivacaine. Curr Opin Anesthesiology. 2008 Oct; 21(5):645-50.

24. Leone S, DI Cianni S, Casati A, Fanelli G. Pharmacology, toxicology and clinical use of new long acting local anesthetics, ropivacaine and levobupivacaine. Acta Biomed. 2008 Aug;79(2):95105

25. Gristwood R W. Cardiac and CNS toxicity of levobupi- vacaine: strength of evidence for advantage over bupivacaine. Drug Safety. 2002;25(3):153-63

26. Mather L E, Changdht. Cardiotoxicity with modern local anesthetics. Is there a safer choice? Drugs. 2001; 61(3):333-42

27. Butterworth J F $4^{\text {th }}$ Models and mechanisms of local anesthetic cardiac toxicity: A Review. RegAnesth Pain Med 2010; 35: 167-7

28. Bernards C, Artu A. Effect of intra cerebro ventricular picrotoxin and muscimol on intravenous bupivacaine toxicity. Anesthesiology. 1993 May;78(5): 902 - 910

29. Chan SK, Karmakar MK, Chui PT. Local anesthesia outside the operating room. Hong Kong Med J. 2002 Apr; 8(2):106-13.

30. Neal et al. ASRA practice advisory on local anesthetic toxicity. Reg Anesth Pain Med. 2010; 35: 152-61.

31. Weinberg GL, Vade Boncouer T, Ramaraju GA, Garcia-Amaro MF, Cwik MJ. Pretreatment or resuscitation with a lipid infusion shifts the dose-response to bupivacaine- induced asystole in rats. Anesthesiology. 1998 Apr; 88(4):1071-5.

32. Weinberg GL, Ripper R, Murphy P, et al. Lipid infusion accelerates removal of bupivacaine and recovery from bupivacaine toxicity in the isolated rat heart. Reg Anesth Pain Med. 2006 JulAug;31(4):296-303

33. Rosenblatt MA, Abel M, Fischer GW, Itzkovich CJ, Eisenkraft JB. Successful use of a 20\% lipid emulsion to resuscitate a patient after a presumed bupivacaine related cardiac arrest. Anesthesiology. 2006 Jul; 105(1):217-8.

34. Litz RJ, Popp M, Stehr SN, Koch T. Successful resuscitation of a patient with ropivacaine induced asystole after axillary plexus block using lipid infusion. Anesthesia. 2006 Aug; 61(8):800-1. 
35. Foxall G, McCahon R, Lamb J, Hardman JG, Bedforth NM. Levobupivacaine induced seizures and cardiovascular collapse treated with Intralipid. Anesthesia 2007 May; 62(5):516-8.

36. McCutchen T, Gerancher JC. Early Intralipid therapy may have prevented bupivacaineassociated cardiac arrest. Reg Anesth Pain Med. 2008 Mar-Apr; 33(2):178-80.

37. Odedra D, Lyons G. Local anesthetic toxicity. Current Anesthesia and Critical Care. 2010 Feb; 21(1):52-4.

38. Leskiw U, Weinberg GL. Lipid resuscitation for local anesthetic toxicity: is it really lifesaving? Curr Opin Anesthesiol. 2009 Oct; 22(5):667-71.

39. ShahS, Gopalkrishnan S, Apuya J, Shah S, Martin T. Use of intralipid in an infant with impending cardiovascular collapse due to local anesthetic toxicity. J Anesth 2009 Aug; 23(3):439-441.

40. Barson AJ, Chistwick ML, Doig CM. Fat embolism in infancy after intravenous fat infusions. Arch Dis Child. 1978 March; 53(3):218-223.

\section{AUTHORS:}

1. Lakshmi Mahajan

2. Ruchi Gupta

3. Anita Kumari

4. Chiteshwar Walia,

5. Jagdeep Sharma,

6. Amrinder Singh

\section{PARTICULARS OF CONTRIBUTORS:}

1. Assistant Professor, Department of Anaesthesia, Sri Guru Ram Das Institute of Medical Sciences \& Research, Amritsar, Punjab.

2. Professor and Head, Assistant Professor, Department of Anaesthesia, Sri Guru Ram Das Institute of Medical Sciences \& Research, Amritsar, Punjab.

3. Associate Professor, Department of Anaesthesia, Sri Guru Ram Das Institute of Medical Sciences \& Research, Amritsar, Punjab.
4. Associate Professor, Department of Anaesthesia, Sri Guru Ram Das Institute of Medical Sciences \& Research, Amritsar, Punjab.

5. PG Student, Department of Anaesthesia, Sri Guru Ram Das Institute of Medical Sciences \& Research, Amritsar, Punjab.

6. PG Student, Department of Anaesthesia, Sri Guru Ram Das Institute of Medical Sciences \& Research, Amritsar, Punjab.

\section{NAME ADDRESS EMAIL ID OF THE CORRESPONDING AUTHOR:}

Dr. Lakshmi Mahajan,

75, Medical Enclave,

Circular Road, Amritsar, Punjab.

E-mail: drlakshmimahajan@gmail.com

Date of Submission: 07/02/2014.

Date of Peer Review: 08/02/2014.

Date of Acceptance: 14/02/2014.

Date of Publishing: 12/02/2014. 